\title{
Theoretical Studies on Dicyanoanthracenes as Organic Semiconductor Materials: Reorganization Energy
}

\author{
Young Hee Park, Yun-Hi Kim, ${ }^{\dagger}$ Soon Ki Kwon, ${ }^{\ddagger}$ In Sun Koo, and Kiyull Yang ${ }^{*}$ \\ Department of Chemistry Education and Research Institute of Natural Science, Gyeongsang National University, \\ Jinju 660-701, Korea.*E-mail:kyang@gnu.ac.kr \\ ${ }^{\dagger}$ Department of Chemistry and Research Institute of Natural Science, Gyeongsang National University, Jinju 660-701, Korea \\ ${ }^{\ddagger}$ School of Materials Science \& Engineering and ERI, Gyeongsang National University, Jinju 660-701, Korea \\ Received January 18, 2010, Accepted March 29, 2010
}

\begin{abstract}
Internal reorganization energy due to the structural relaxation in hole or electron hopping mechanism is one of the measurements of key indices in designing an organic thin film transistor (OTFT) for flexible display devices. In this study, the reorganization energies of dicyanoanthracenes for the hole and electron transfer were estimated by adiabatic potential energy surface and normal mode analysis method in order to examine the effect on the energies for the positional variation of the cyano substituents in the anthracene as a protocol of acenes to design an organic field effect transistor. The reorganization energy for the hole transfer was reduced considerably upon cyanation of anthracene, especially at the 9,10positions of anthracene, and the origin of the reduction was interpreted in terms of understanding the coupling of vibrational modes to the hole transfer.
\end{abstract}

Key Words: Reorganization energy, Hole or electron hopping, Organic thin film transistor, Dicyanoanthracenes, Density functional theory

\section{Introduction}

Among organic semiconductor materials, conjugated organic molecules have been increasingly used as active materials for optoelectronic devices such as field-effect transistors (FET's), ${ }^{1-5}$ light-emitting diodes (LED's), ${ }^{6-9}$ and photovoltaic and solar cells. ${ }^{10-13}$ The devices fabricated by using organic semiconductors are known as organic devices, and organic thin film transistors (OTFT) are one class of these devices. ${ }^{14}$ This transistor is one of the key components for the switching circuitry for use in flexible display devices.

These materials used in OTFTs offer advantages of easy fabrication, mechanical flexibility and low cost. A number of organic materials including acenes and their derivatives show useful field-effect transistor performance, which can be characterized by their carrier mobility and on/off current ratios. Among the acene-related compounds, pentacene is the most popular molecule as it shows good carrier (hole) mobility up to $\sim 5 \mathrm{~cm}^{2} /$ Vs, exceeding that of amorphous silicon transistors. ${ }^{15-17}$

Despite its adequate charge transport properties, pentacene suffers from chemical instability and insolubility. ${ }^{18,19}$ Therefore, numerous attempts have been made to enhance both of these properties by structural modification. ${ }^{20-24}$

Among the acenes, anthracene and its derivatives also have attracted considerable interest since they have interesting photoluminescence (PL), electroluminescence (EL), and electrochemical properties. ${ }^{25-27}$

Together with research on acene derivatives, studies on many derivatives of heterocyclic oligomers have been reported both experimentally and theoretically. ${ }^{28-30}$ In one notable study, Marks and coworkers ${ }^{31}$ discussed substituent effects of oligomers such as oligothiophene, oligopyrrole and oligofuran in terms of reorganization energy $(\lambda)$, which will be discussed later in detail.

Based on the examination of the data presented in Marks' work, it was found that the cyano group $(\mathrm{CN})$ shows lower reorganization energy than any other simple substituents such as $-\mathrm{F}$, $-\mathrm{CF}_{3}$ and $\mathrm{NH}_{2}$. Oliveira et al. ${ }^{32}$ also reported geometries and electronic properties for cyanothiophene oligomers as a prototype of an organic conducting polymer using ab initio and density functional theory (DFT), ${ }^{33}$ and they showed that the $\mathrm{CN}$ group generally reduced the band gap with variation of the substitution position. Very recently Kuo et al. reported the effectiveness of cyanation on pentacene in designing of $n$-type organic FETs. ${ }^{34}$ Thus, studies to re-estimate the properties of organic semiconductor materials are being increasingly performed, and it is known that estimation of the mobility of organic semiconductor materials is possible through estimation of the reorganization energy.

Therefore, it is quite valuable to examine the cyano group substituent effect on acene molecule varying the position of the substituent. For this purpose, an anthracene molecule is one of the simple acenes showing optoelectronic properties and structural similarities to well-known OTFT materials, and an anthracene unit along with the pentacene is widely used as a parent molecule in designing organic semiconductors.

In the present work, we have performed density functional theory studies on the reorganization energy and some electronic structures such as band gap of the dicyanoanthracenes depicted in Figure 1 to examine the effects of the position of the substituents. In particular, all reorganization energies related to the hole hopping and the electron hopping are discussed. The cause of the dependency of reorganization energy of dicyanoanthracene on the position of substitution of the cyano group is studied using a normal-mode frequency analysis. 
<smiles>c1ccc2cc3ccccc3cc2c1</smiles>

1<smiles>N#Cc1c2ccccc2c(C#N)c2ccccc12</smiles><smiles>N#Cc1cc2cc3ccccc3cc2cc1C#N</smiles>

2<smiles>N#Cc1ccc(C#N)c2cc3ccccc3cc12</smiles><smiles>N#Cc1cccc2cc3c(C#N)cccc3cc12</smiles>

Figure 1. Structures of anthracene and its derivatives discussed in this work.

\section{Computational Method}

Many theoretical characterizations including the charge transport properties of organic materials for the OTFTs are well described by Brédas et $a l .{ }^{35}$ The work was mainly achieved by using the DFT and show the reliability of the DFT to reproduce experimental findings. The measured hole and electron mobilities of oligoacene crystals show a band hopping transition occurring at about room temperature.

Hopping of hole or electron can be described as an electron transfer (ET) reaction from a charged, relaxed unit to an adjacent neutral unit, and the mobility depends on the electron transfer rate. The hole transport in the $p$-type organic semiconductor materials can be described as a self-exchange reaction (1).

$$
\mathrm{M}^{+}+\mathrm{M} \rightarrow \mathrm{M}+\mathrm{M}^{+}
$$

Here, $\mathrm{M}^{+}$refers to the molecule in the cationic state, and $\mathrm{M}$ refers to the adjacent molecule in the neutral state. At high temperatures, the hopping rates for the self-exchange reactions are given in Eq. (2), according to the semi-classical Marcus theory. ${ }^{36}$

$$
k_{E T}=\frac{4 \pi^{2}}{h} \frac{1}{\sqrt{4 \pi \lambda k_{B} T}} t^{2} \exp \left(-\frac{\lambda}{4 k_{B} T}\right)
$$

Here, $\lambda$ is a reorganization energy that describes the strength of hole (electron)-vibration coupling energy of a charge localized on a single molecule, and it needs to be small for efficient transport. The electronic coupling term $(t)$ between two adjacent molecules, often called transfer integral largely depends upon the orbital overlap between those, and it needs to be large for higher mobility. ${ }^{37}$ The intramolecular reorganization energy is a purely intrinsic property of a single molecule, and the energy consists of two terms corresponding to the structural relaxation energies $\lambda_{\mathrm{N}}$ and $\lambda_{\mathrm{C}}$, as illustrated in Figure 2 .

The reorganization energies can be estimated in two ways, with an adiabatic process using adiabatic potential energy surface, shown in Figure 2, and with a normal-mode analysis. In the former procedure, total adiabatic reorganization energy $\left(\lambda_{\text {tot }}=\right.$ $\left.\lambda_{\mathrm{N}}+\lambda_{\mathrm{C}}\right)$ is a sum of the relaxation or reorganization energies given in Eqs. (3) and (4), ${ }^{37-41}$

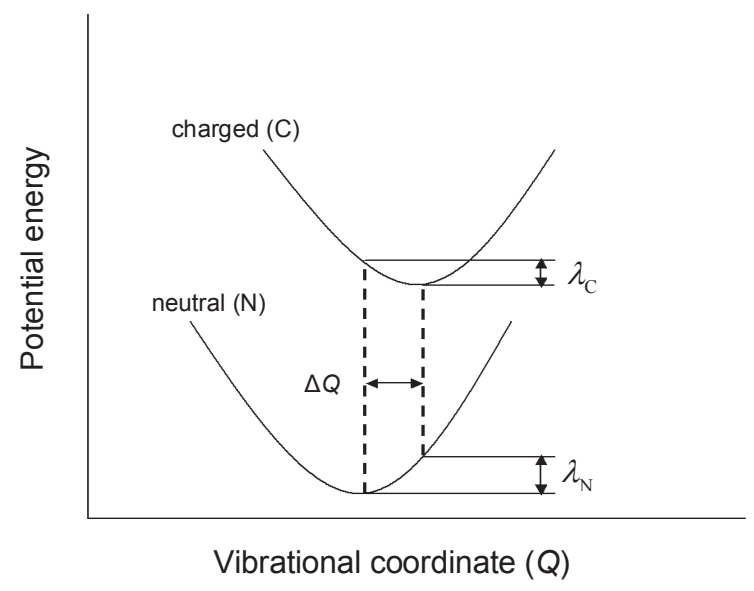

Figure 2. Schematic diagram of general adiabatic energy surfaces corresponding to the ionization process. $Q$ is a normal-mode displacement and $\lambda_{\mathrm{N}}$ and $\lambda_{\mathrm{C}}$ are relaxation energies described at Eqs. 3 and 4, respectively.

$$
\begin{aligned}
& \lambda_{\mathrm{N}}=E_{\mathrm{N}}(r e l)-E_{\mathrm{N}} \\
& \lambda_{\mathrm{C}}=E_{\mathrm{C}}(r e l)-E_{\mathrm{C}}
\end{aligned}
$$

where $E_{\mathrm{N}}(\mathrm{rel})$ and $E_{\mathrm{C}}(\mathrm{rel})$ are the energies of neutral state in the optimized (relaxed) geometry of a charged (cationic or anionic) molecule and the energies of a charged state in the optimized geometry of a neutral molecule, respectively. $E_{\mathrm{N}}$ and $E_{\mathrm{C}}$ are the energies of the neutral state in the optimized geometry of a neutral molecule and the energies of the charged state in the optimized geometry of a charged molecule, respectively.

In the latter procedure, the total reorganization energies can be estimated by summing over the contributions of each vibrational mode based on harmonic oscillation approximation:

$$
\lambda_{N(C)}=\sum \lambda_{i}=\sum \frac{1}{2} k_{i} \Delta Q_{i}^{2}
$$

where $\Delta Q_{i}$ represents the displacement along vibrational coordinate $Q_{i}$ between the geometries of the two states, and $k_{i}$ is the corresponding force constant.

All quantum mechanical calculations were performed using the Gaussian 98 program, ${ }^{42}$ and the structures and the adiabatic reorganization energies were evaluated at the DFT of Becke's 3-parameter hybrid method using the correlation functional of Lee, Yang, and Parr (B3LYP) ${ }^{43}$ at the 6-31G(d,p) level. Total adiabatic reorganization energies were calculated using Eqs.(3) and (4), and the evaluation of reorganization energies represented by Eq. (5) with normal mode analysis were performed by the DUSHIN program written by Reimers. ${ }^{40}$ ZINDO method ${ }^{44}$ was applied to evaluated band gaps along with DFT and HartreeFock (HF) geometries of the molecules.

\section{Results and Discussion}

We calculated the reorganization energies of 9,10-disubstitut- 
Table 1. Calculated reorganization energies $(\mathrm{eV})$ of anthracene and its derivatives for hole and electron hopping with Hammett substituent constants

\begin{tabular}{|c|c|c|c|c|c|c|c|}
\hline & \multicolumn{3}{|c|}{ Hole hopping } & \multicolumn{3}{|c|}{ Electron hopping } & \\
\hline & $\lambda_{\mathrm{N}}$ & $\lambda_{\mathrm{C}}$ & $\lambda_{\text {tot }}$ & $\lambda_{\mathrm{N}}$ & $\lambda_{\mathrm{C}}$ & $\lambda_{\text {tot }}$ & \\
\hline $\mathrm{OH}$ & 0.147 & 0.145 & 0.292 & 0.124 & 0.124 & 0.248 & -0.37 \\
\hline $\mathrm{OCH}_{3}$ & 0.173 & 0.169 & 0.342 & 0.134 & 0.133 & 0.267 & -0.27 \\
\hline $\mathrm{CH}_{3}$ & 0.074 & 0.075 & 0.149 & 0.094 & 0.096 & 0.189 & -0.17 \\
\hline $\mathrm{H}$ & 0.068 & 0.069 & 0.137 & 0.099 & 0.101 & 0.200 & 0.0 \\
\hline $\mathrm{F}$ & 0.108 & 0.107 & 0.215 & 0.117 & 0.118 & 0.235 & 0.06 \\
\hline $\mathrm{Cl}$ & 0.094 & 0.094 & 0.188 & 0.108 & 0.106 & 0.213 & 0.23 \\
\hline $\mathrm{Br}$ & 0.089 & 0.089 & 0.178 & 0.105 & 0.105 & 0.209 & 0.23 \\
\hline $\mathrm{CN}$ & 0.053 & 0.0504 & 0.107 & 0.100 & 0.099 & 0.199 & 1.00 \\
\hline
\end{tabular}

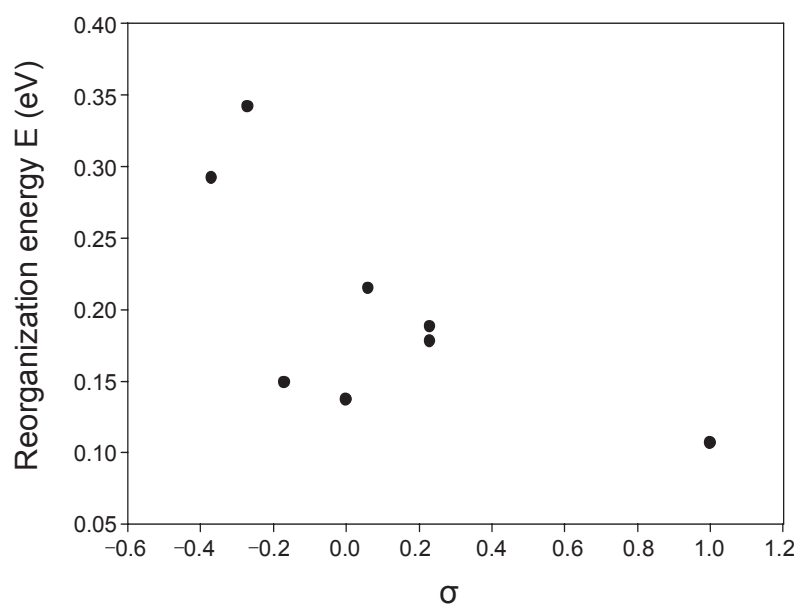

Figure 3. Plots of the computed reorganization energies for hole hopping against Hammett parameters.

ed-anthracenes as $p$ - and $n$-type semiconductors, where the substituents were located at the central position of the anthracene moiety for the preliminary examination. Calculated reorganizations are summarized in Table 1, and we attempted to relate the $p$-type reorganization energies to the Hammett substituent constants $(\sigma)^{45}$ as shown in Figure 3.

The reorganization energy was reduced significantly upon substitution of the $\mathrm{CN}$ group in anthracene, especially for positive doping (hole hopping). However, it did not show a good linear relationship with the Hammett parameter $(\sigma)$ although a general tendency could be observed. Moreover, we also could not find any considerable linear relationship between the electron hopping reorganization energy and the Hammett parameters.

To examine the effect on the reorganization energy for the positional variation of the cyano substituents we calculated reorganization energies of molecules displayed in Figure 1.

Reorganization energies for the hole-transport reaction obtained by adiabatic potential energy surface (AP) and normal mode analyses (NM) are presented in Table 2.

Energies obtained by the two methods were almost the same, and the value of anthracene was in good agreement with the values reported by others. ${ }^{46}$ As shown in Table 2 , reorganization
Table 2. Hole transfer reorganization energies $(\mathrm{eV})$ of dicyanoanthracenes in Figure 1

\begin{tabular}{ccccc}
\hline molecule & method $^{a}$ & $\lambda_{\mathrm{N}}$ & $\lambda_{\mathrm{C}}$ & $\lambda_{\text {tot }}$ \\
\hline \multirow{2}{*}{$\mathbf{1}$} & AP & 0.069 & 0.070 & 0.139 \\
& $\mathrm{NM}$ & 0.071 & 0.069 & 0.140 \\
$\mathbf{2}$ & $\mathrm{AP}$ & 0.065 & 0.065 & 0.130 \\
& $\mathrm{NM}$ & 0.066 & 0.064 & 0.130 \\
$\mathbf{3}$ & $\mathrm{AP}$ & 0.065 & 0.066 & 0.131 \\
& $\mathrm{NM}$ & 0.067 & 0.065 & 0.132 \\
$\mathbf{4}$ & $\mathrm{AP}$ & 0.053 & 0.054 & 0.107 \\
& $\mathrm{NM}$ & 0.054 & 0.053 & 0.107 \\
$\mathbf{5}$ & AP & 0.066 & 0.065 & 0.131 \\
& $\mathrm{NM}$ & 0.066 & 0.065 & 0.131 \\
$\mathbf{6}$ & $\mathrm{AP}$ & 0.060 & 0.061 & 0.121 \\
& $\mathrm{NM}$ & 0.061 & 0.060 & 0.121 \\
\hline
\end{tabular}

$\overline{{ }^{a} \mathrm{AP} \text { and NM refer to the adiabatic potential surfaces method and normal }}$ mode method, respectively.

Table 3. Vibrational frequencies $\omega\left(\mathrm{cm}^{-1}\right)$, normal-mode displacement $Q$, and relaxation energies $\lambda$ (in $\mathrm{eV}$ ) associated with the totally symmetric vibrations of anthracene in neutral and singly oxidized states

\begin{tabular}{ccccccc}
\hline & neutral & & & \multicolumn{3}{c}{ cation } \\
\cline { 1 - 4 } \cline { 5 - 7 } 1194 & $Q$ & $\lambda_{\mathrm{N}, \omega}$ & & $\omega$ & $Q$ & $\lambda_{\mathrm{C}, \omega}$ \\
\hline 1300 & -0.214 & 0.003 & & 1207 & -0.236 & 0.004 \\
1444 & 0.434 & 0.017 & & 1426 & -0.551 & 0.027 \\
1530 & -0.146 & 0.002 & & 1545 & -0.313 & 0.009 \\
1608 & -0.629 & 0.039 & & 1611 & 0.504 & 0.025 \\
total & & 0.071 & & & 0.069 \\
\hline
\end{tabular}

energies of all derivatives were lower than that of anthracene, $\mathbf{1}$, and 9,10-dicyanoanthracene, 4 showed the lowest reorganization energy, which is similar to that of pentacene, i.e., $0.097 \mathrm{eV}$. The rest of the derivatives showed almost the same reorganization energies of about $0.130 \mathrm{eV}$. Positions 2,6 or symmetric both ends of the acene unit, as in molecule 5 , are commonly used positions for the design of functionalized anthracene or pentacene units to alter molecular packing ability and to increase solubility.

The partition of the hole transfer reorganization energy of anthracene into its contribution to each vibrational mode is given in Table 3. The larger contributions to the reorganization energy come from the vibrations at around 1444 and $1608 \mathrm{~cm}^{-1}$ in a neutral state of anthracene. The largest one corresponds to the vibration at $1608 \mathrm{~cm}^{-1}$ in a neutral state, which contributes by half to the reorganization energy. The mode that corresponds to this vibration is symmetric stretching of four vertical $C=C$ bonds, as depicted in Figure 4, while the vibration at $1444 \mathrm{~cm}^{-1}$ in a neutral state corresponds to anti-symmetric stretching of four vertical $\mathrm{C}=\mathrm{C}$ bonds; the anti-symmetric here denotes that two of the vertical $\mathrm{C}=\mathrm{C}$ bonds in the central position are lengthening, while the other vertical $\mathrm{C}=\mathrm{C}$ bonds in both ends are shortening. Both vibrations are corresponding to 'latitudinal' lengthening of the molecule, and substitution on the latitudinal 


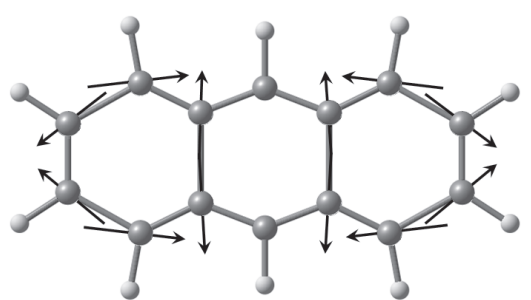

$\omega=1444 \mathrm{~cm}^{-1}$

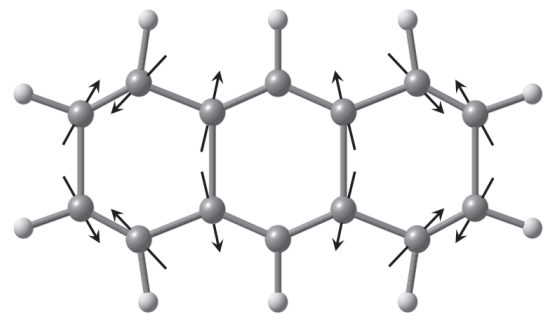

$\omega=1608 \mathrm{~cm}^{-1}$

Figure 4. Snap shot of stretching modes of anti-symmetric stretching (left) and symmetric stretching (right) in anthracene with respect to the vertical four $\mathrm{C}-\mathrm{C}$ bonds.

position seems to reduce the reorganization energies such as compounds $\mathbf{4}$ and $\mathbf{6}$.

The partitions of the hole transfer reorganization energies for the neutral state in the dicyanoanthracenes are given in Table 4 . In the table, only one part of reorganization energy $\lambda_{\mathrm{N}}$ is partitioned into corresponding vibrations for clarity since the other part of the reorganization energy $\lambda_{\mathrm{C}}$ is almost the same as $\lambda_{\mathrm{N}}$ with slight alteration of the frequency as seen in the anthracene (see Tables 2 and 3). Graphical representation of the partitions is depicted in Figure 5.

As shown in Table 4 and Figure 5, the reorganization energy decreased, especially around $1600 \mathrm{~cm}^{-1}$ when the $\mathrm{CN}$ groups were substituted at the 9,10 positions. Upon ionization to cation, the electron in the highest occupied molecular orbital (HOMO), which was a $\pi$ bonding molecular orbital, was removed and the effect on reorganization energy was the largest around 1600 $\mathrm{cm}^{-1}$, which corresponds to $\mathrm{C}=\mathrm{C}$ double bond stretching as shown in Figure 4.

Net charge density calculated by the Mulliken population analysis and atomic orbital (AO) coefficients of the nitrogen atom in the HOMO are summarized in Table 5 and other indices to support this charge transfer. As shown in Table 5, the charge density and the AO coefficient of the nitrogen atom in $\mathbf{4}$ were the largest among those of the dicyanoanthracenes in this study. We plot the reorganization energies versus the AO coefficients in Figure 6. As shown in the figure, one can see a very good linear relationship between the reorganization energy and the nitrogen AO coefficients in the HOMO. This implies that the electron density was more localized on the nitrogen atom in the HOMO, and thus the electron density in the nitrogen atom could be ionized more than that in the carbon $\pi$ orbital frame.

The lowest reorganization energy of the 9,10-dicyanoanthracene, 4 can be ascribed to the fact that electrons were more localized at the $\mathrm{CN}$ group, especially at the $\mathrm{N}$ atom. Thus, delo-
Table 4. Vibrational frequencies $\omega\left(\mathrm{cm}^{-1}\right)$ and reorganization energies $\lambda_{\mathrm{N}}(\mathrm{eV})^{a}$ associated to the totally symmetric vibrations of dicyanoanthracene in neutral states.

\begin{tabular}{|c|c|c|c|c|c|c|c|}
\hline 2 & \multicolumn{2}{|c|}{3} & \multicolumn{2}{|c|}{4} & \multicolumn{2}{|c|}{5} & 6 \\
\hline$\lambda_{\mathrm{N}, \omega}$ & $\omega$ & $\lambda_{\mathrm{N}, \omega}$ & $\omega$ & $\lambda_{\mathrm{N}, \omega}$ & $\omega$ & $\lambda_{\mathrm{N}, \omega}$ & $\lambda_{\mathrm{N}, \omega}$ \\
\hline 13140.009 & 1032 & 0.009 & 1313 & 0.007 & 1302 & 0.005 & 13950.011 \\
\hline 14430.013 & 1419 & 0.005 & 1454 & 0.016 & 1308 & 0.006 & 14410.011 \\
\hline 16050.033 & 1434 & 0.008 & 1609 & 0.026 & 1450 & 0.016 & 16080.028 \\
\hline & 1609 & 0.032 & & & 1598 & 0.035 & \\
\hline
\end{tabular}

${ }^{a}$ The vibrations which correspond to the reorganization energy of $0.002 \mathrm{eV}$ or more are summarized.

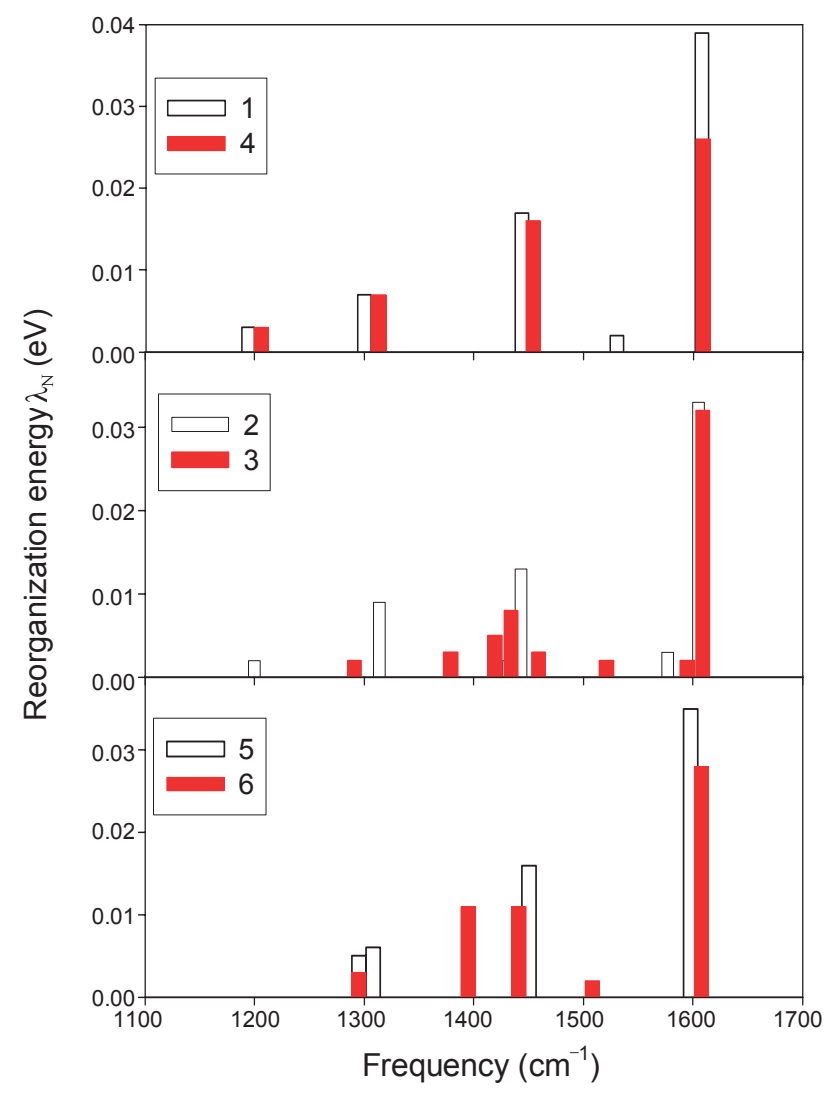

Figure 5. Comparison of hole hopping reorganization energy at vibrational frequencies for anthracene and dicyanoanthracenes. Only $\lambda_{N}$ values are displayed for clarity.

calized $\pi$ electrons in the aromatic backbone of 9,10-dicyanoanthracene were relatively smaller than those in others, and the deformation caused by the ionization is smaller than those in the others.

We also summarized the HOMO $\pi$-electron population of the carbon skeleton of the neutral and cationic molecules and the root-mean-square $(r m s)$ deviation between coordinates of neutral and cationic molecules.

As shown in Table 5, the decrease in the $\pi$-electron population was the smallest in the 9,10 position (4). The ratio of the $\pi$-electron population in molecule 4 over molecule 1 was $81 \%$, which is similar to that of the reorganization energy (78\%). Therefore, 
Table 5. Electron populations ( $\rho$ in $\boldsymbol{e}$ ), atomic orbital coefficients $(C)$ and geometry change in terms of $r m s$ deviation (in $\AA$ ) upon ionization of dicyanoanthracenes

\begin{tabular}{ccccccc}
\hline $\begin{array}{c}\text { mole- } \\
\text { cule }\end{array}$ & $\rho_{\mathrm{N}}{ }^{a}$ & $C_{\mathrm{N}}^{\text {homo } b}$ & $\rho_{\mathrm{M}}^{\text {homo } c}$ & $\rho_{\mathrm{M}^{+}}^{\text {homo }}$ & $-\Delta \rho^{c}$ & $\begin{array}{c}r m s \\
\text { deviation }\end{array}$ \\
\hline 1 & - & - & 0.581 & 0.253 & 0.328 & 0.0101 \\
2 & -0.4702 & 0.1236 & 0.558 & 0.239 & 0.319 & 0.0097 \\
3 & -0.4823 & 0.1149 & 0.560 & 0.235 & 0.325 & 0.0157 \\
4 & -0.4973 & 0.1823 & 0.473 & 0.208 & 0.265 & 0.0083 \\
5 & -0.4733 & 0.1237 & 0.565 & 0.235 & 0.330 & 0.0102 \\
6 & -0.4884 & 0.1460 & 0.550 & 0.232 & 0.318 & 0.0099
\end{tabular}

${ }^{a}$ Net charge density of nitrogen atom. ${ }^{b}$ Atomic orbital coefficient of $\mathrm{N}$ atom in HOMO. ${ }^{c}$ Total and decrease $(-\Delta \rho)$ of HOMO $\pi$-electron populations of carbon backbone

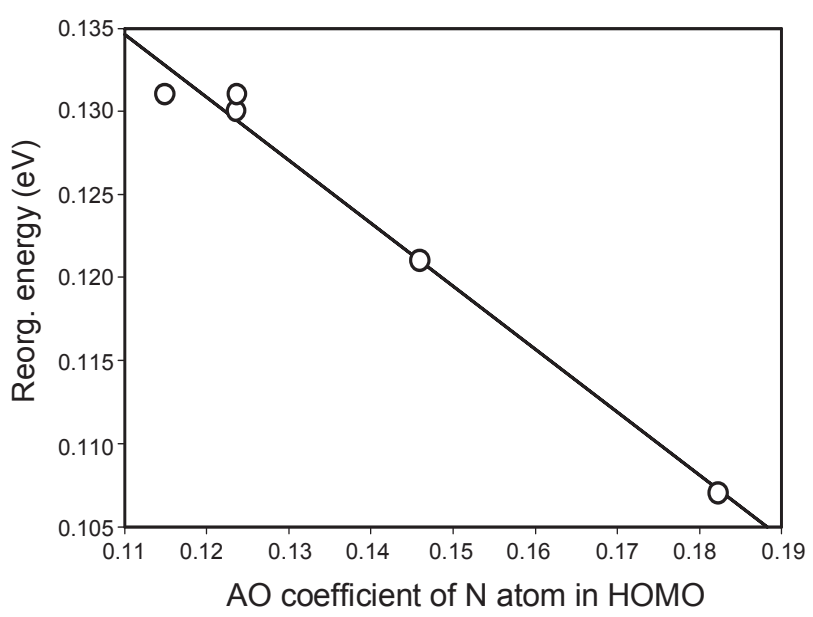

Figure 6. The linear relationship between $\mathrm{AO}$ coefficient of nitrogen atom and reorganization energy.

substitution of the $\mathrm{CN}$ group reduced the $\pi$-electron population in $\mathrm{HOMO}$, and this led to a decrease in geometry deformation in anthracene when molecules were ionized to cations. This effect of the $\mathrm{CN}$ group was the largest in the 9,10 positions of anthracene. This is clear upon inspection of the change of the geometry in terms of $r m s$ deviation between the neutral molecule and the cationic molecule. The rms deviation for the $\mathbf{4}$ was the smallest among the derivatives, as shown in Table 5.

This discussion related to the $\mathrm{CN}$ group can be applied to the pentacene molecule. We calculated the reorganization energies of pentacene and dicyanopentacene using the normal mode (NM) method, and the results are summarized in Table 6. The total reorganization energy of pentacene and dicyanopentacene for the hole transfer are $0.095 \mathrm{an} 0.072 \mathrm{eV}$, respectively. These values are almost the same as values reported, ${ }^{34,35}$ and the reorganization energy of the dicyanopentacene was significantly reduced upon the dicyanation. As shown in Table 6 the change in the relaxation energy is the largest around $1570 \mathrm{~cm}^{-1}$ when the $\mathrm{CN}$ group was substituted in pentacene, and this frequency corresponds to $\mathrm{C}=\mathrm{C}$ double bond stretching vibration, which is a similar mode in the anthracene (see Fig. 4 (right)).

Examination of geometry change in terms of rms deviation between neutral and cationic structures reveals that $\mathrm{CN}$ groups in
Table 6. Vibrational frequencies $\omega\left(\mathrm{cm}^{-1}\right)$ and reorganization energies $\lambda_{\mathrm{N}}(\mathrm{eV})^{a}$ associated to the totally symmetric vibrations of dicyanoanthracene in neutral states

\begin{tabular}{|c|c|c|c|c|c|c|c|}
\hline \multicolumn{4}{|c|}{$\begin{array}{c}\text { pentacene (pen) } \\
\left(\lambda_{\text {tot }}=0.095\right)\end{array}$} & \multicolumn{4}{|c|}{$\begin{array}{c}\text { dicyanopentacene }(\text { pen-CN }) \\
\left(\lambda_{\text {tot }}=0.072\right)\end{array}$} \\
\hline \multicolumn{2}{|c|}{ neutral } & \multicolumn{2}{|c|}{ cation } & \multicolumn{2}{|c|}{ neutral } & \multicolumn{2}{|c|}{ cation } \\
\hline$\omega$ & $\lambda_{\mathrm{N}, \omega}$ & $\omega$ & $\lambda_{\mathrm{C}, \omega}$ & $\omega$ & $\lambda_{\mathrm{N}, \omega}$ & $\omega$ & $\lambda_{\mathrm{C}, \omega}$ \\
\hline 1217 & 0.007 & 1227 & 0.007 & 1237 & 0.005 & 1248 & 0.005 \\
\hline 1425 & 0.013 & 1441 & 0.017 & 1435 & 0.011 & 1432 & 0.004 \\
\hline \multirow[t]{2}{*}{1570} & 0.018 & 1560 & 0.011 & 1568 & 0.006 & 1445 & 0.010 \\
\hline & & 1590 & 0.007 & 1593 & 0.007 & 1590 & 0.009 \\
\hline
\end{tabular}

Table 7. Reorganization energies (eV) for electron hopping in anthracene and dicyanoanthracenes

\begin{tabular}{ccccc}
\hline molecule & method $^{a}$ & $\lambda_{\mathrm{N}}$ & $\lambda_{\mathrm{C}}$ & $\lambda_{\text {tot }}$ \\
\hline \multirow{2}{*}{$\mathbf{1}$} & $\mathrm{AP}$ & 0.099 & 0.100 & 0.199 \\
& $\mathrm{NM}$ & 0.101 & 0.099 & 0.200 \\
$\mathbf{2}$ & $\mathrm{AP}$ & 0.082 & 0.084 & 0.166 \\
& $\mathrm{NM}$ & 0.084 & 0.082 & 0.166 \\
$\mathbf{3}$ & $\mathrm{AP}$ & 0.105 & 0.107 & 0.212 \\
& $\mathrm{NM}$ & 0.108 & 0.105 & 0.213 \\
$\mathbf{4}$ & $\mathrm{AP}$ & 0.100 & 0.099 & 0.199 \\
& $\mathrm{NM}$ & 0.102 & 0.100 & 0.202 \\
$\mathbf{5}$ & $\mathrm{AP}$ & 0.093 & 0.092 & 0.185 \\
& $\mathrm{NM}$ & 0.095 & 0.090 & 0.185 \\
$\mathbf{6}$ & $\mathrm{AP}$ & 0.098 & 0.099 & 0.197 \\
& $\mathrm{NM}$ & 0.100 & 0.098 & 0.198
\end{tabular}

$\overline{{ }^{a} \mathrm{AP} \text { and NM refer to the adiabatic potential surfaces method and normal }}$ mode method, respectively.

the central position reduced the deformation of carbon backbone on ionization: the rms deviations for the pentacene and dicyanopentacene are $0.0085 \AA$ and $0.0068 \AA$, respectively. The derease $\left(-\Delta \rho=\rho_{\mathrm{M}^{+}}^{\text {homo }}-\rho_{\mathrm{M}}^{\text {homo }}\right)$ of HOMO $\pi$-electron population in pentacene and dicyanopentacene are $0.306 \boldsymbol{e}$ and $0.229 \boldsymbol{e}$, respectively. This implies that the electron population is more localized in the $\mathrm{CN}$ group and resulted in smaller reorganization in the dicyanopentacene. It is worth noting that the amount of decrease in $\pi$ electron population in dicyanopentacene (25\%) is well in agreement with the decrease in the reorganization energy (24\%).

We also calculated the reorganization energies of dicyanoanthracenes for electron hopping, where anthracenes are used as negative type ( $n$-type) organic semiconductor materials. Computational results obtained from both adiabatic (AP) and normal mode (NM) analysis are summarized in Table 7.

As shown in Table 7, the reorganization energies for electron transfer were larger than those for the hole transfer process by about $0.07 \mathrm{eV}$, although $\mathrm{CN}$ is an electron-withdrawing group. Reorganization energies were partitioned into the individual vibrational frequencies, and are summarized in Table 8 for the anthracene and dicyanoanthracens. Inspection of the vibrationcoupling frequencies for electron hopping in the anthracene re- 
Table 8. Vibrational frequencies $\omega\left(\mathrm{cm}^{-1}\right)$ and relaxation energies $\lambda_{\mathrm{N}}(\mathrm{eV})$ associated with the totally symmetric vibrations of dicyanoanthracenes in neutral state

\begin{tabular}{|c|c|c|c|c|c|c|c|c|c|c|c|}
\hline \multicolumn{2}{|c|}{1} & \multicolumn{2}{|c|}{2} & \multicolumn{2}{|c|}{3} & \multicolumn{2}{|c|}{4} & \multicolumn{2}{|c|}{5} & \multicolumn{2}{|c|}{6} \\
\hline$\omega$ & $\lambda_{\mathrm{N}, \omega}$ & $\omega$ & $\lambda_{\mathrm{N}, \omega}$ & $\omega$ & $\lambda_{\mathrm{N}, \omega}$ & $\omega$ & $\lambda_{\mathrm{N}, \omega}$ & $\omega$ & $\lambda_{\mathrm{N}, \omega}$ & $\omega$ & $\lambda_{\mathrm{N}, \omega}$ \\
\hline 399 & 0.027 & 327 & 0.018 & 326 & 0.018 & 425 & 0.019 & 304 & 0.014 & 124 & 0.004 \\
\hline 1194 & 0.006 & 1314 & 0.007 & 1225 & 0.004 & 684 & 0.005 & 1187 & 0.005 & 379 & 0.014 \\
\hline 1300 & 0.010 & 1443 & 0.028 & 1379 & 0.006 & 1206 & 0.004 & 1308 & 0.006 & 1395 & 0.013 \\
\hline 1444 & 0.034 & 1577 & 0.006 & 1419 & 0.025 & 1313 & 0.031 & 1450 & 0.027 & 1441 & 0.033 \\
\hline \multirow[t]{3}{*}{1608} & 0.020 & 1605 & 0.009 & 1546 & 0.008 & 1531 & 0.005 & 1598 & 0.012 & 1608 & 0.019 \\
\hline & & & & 1592 & 0.004 & 1609 & 0.022 & 1676 & 0.015 & 2340 & 0.004 \\
\hline & & & & 2309 & 0.004 & 2332 & 0.011 & 2347 & 0.006 & & \\
\hline
\end{tabular}

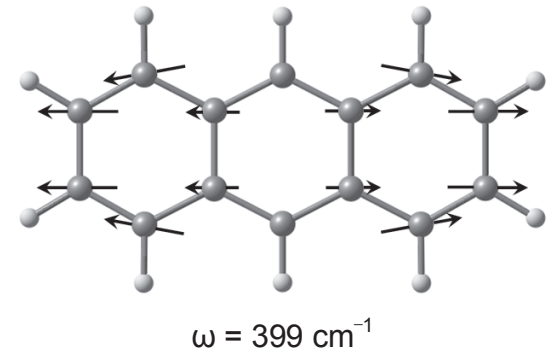

Figure 7. Displacement vectors for the one of the normal modes which show larger vibrational coupling for the electron hopping in anthracene.

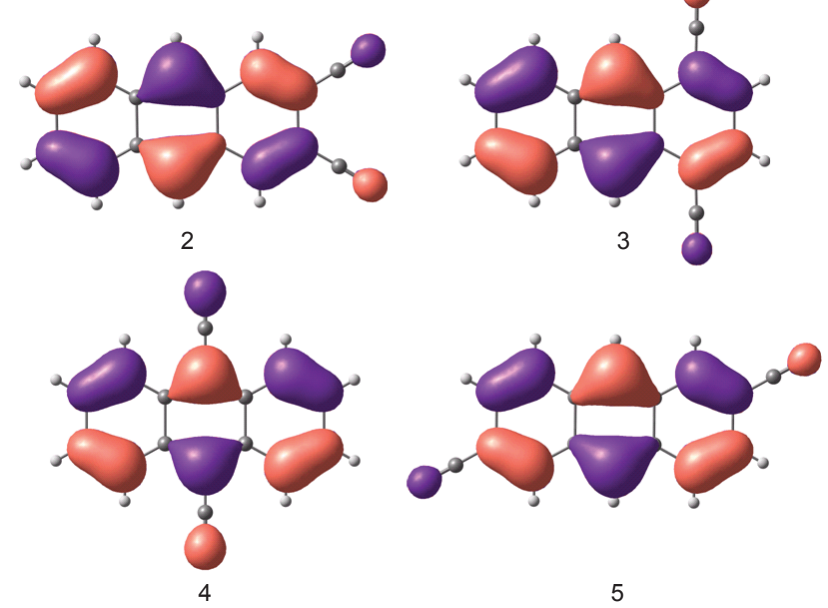

Figure 8. HOMO of dicyanoanthracenes obtained by B3LYP/6-31G $(d, p)$.

vealed an additional spectrum at around $400 \mathrm{~cm}^{-1}$, which corresponds to a kind of bending vibration as depicted in Figure 7. This vibration caused expansion of the molecule along the longitudinal axes as an electron was added to the neutral anthracene molecule, and the reorganization energy was then increased by about $0.06 \mathrm{eV}$ as compared with that of the hole hopping.

Examination of the geometries of the neutral and anionic state of anthracene revealed that the change of the longitudinal length of the molecule was about $0.08 \AA$ upon addition of the electron and this change corresponded to about $0.06 \mathrm{eV}$ in the reorga-
Table 9. Calculated energy gap $(\mathrm{eV})$ for the anthracene and dicyanoanthracenes

\begin{tabular}{lcccccc}
\hline \multicolumn{1}{c}{ Compound Method } & $\mathbf{1}$ & $\mathbf{2}$ & $\mathbf{3}$ & $\mathbf{4}$ & $\mathbf{5}$ & $\mathbf{6}$ \\
\hline ZINDO//B3LYP/6-31G(d,p) & 3.45 & 3.35 & 3.25 & 3.19 & 3.35 & 3.45 \\
ZINDO//HF/6-31G(d,p) & 3.53 & 3.41 & 3.27 & 3.16 & 3.40 & 3.40 \\
B3LYP/6-31G(d,p)// & 3.59 & 3.40 & 3.14 & 2.96 & 3.38 & 3.35 \\
B3LYP/6-31G(d,p) & 3.27 & 3.05 & 2.70 & 2.84 & 3.02 & 3.06 \\
TD-DFT & $3.53 \sim 3.68$ & & & & & \\
B3LYP/6-31G(d,p)//cryst. & $3.28 ~ 3.42$ & & & &
\end{tabular}

Experimental energy gap of anthracene $^{a}$

$4.10^{b}, 4.40^{c}$

nization energy of the electron-hopping. A similar degree of molecular expansion $(0.06 \sim 0.07 \AA)$ occurred in the dicyanoanthracenes, and this caused increased reorganization energies of $n$-type doping. However, the relationship between the energies and variations of the position of substituents are less clear than that in the hole transfer, although there is a tendency to lower the reorganization of the longer the molecules such as $\mathbf{2}$ and $\mathbf{5}$, where the substituent makes the molecule longer in longitudinal direction.

We also calculated band gaps for the dicyanoanthracene using several methods, and the gaps are summarized in Table 9. The band gaps estimated by Zindo method and B3LYP DFT exhibited the lowest excitation energy and energy difference between HOMO and LUMO energy level $\left(\varepsilon_{\text {LUMO }}-\varepsilon_{\text {HOMO }}\right){ }^{47}$ respectively. For geometry optimization, both the $\mathrm{HF} / 6-31 \mathrm{G}(\mathrm{d}, \mathrm{p})$ and B3LYP/6-31G(d,p) methods were used, and experimental geometries of anthracene were used for the estimation of band gap for a comparison. Experimental values for the electrical (adiabatic) band gap and optical band gap of anthracene were 4.1 and $4.40 \mathrm{eV}$, respectively. ${ }^{48}$

Though the estimated band gaps of anthracene using several methods and geometries were underestimated compared to the experimental value, the values were very similar to each other. However, the trends of estimated band gaps were all the same in any methods of estimation. As shown in Table 9, cyanation on 
anthracene lowered the band gap, and the band gap of 9,10-dicyanoanthracene was the smallest among them.

\section{Conclusions}

In order to elucidate the positional preference in cyanation on acene molecule, which can be used as organic semiconductor materials in thin film transistors (TFTs), we have estimated reorganization energies of some dicyanoanthracenes as a theoretical benchmark. The reorganization energies for the hole and electron transfer were estimated by adiabatic potential energy surface and normal mode analysis method at the basis of B3LYP/ 6-31G(d,p).

The reorganization energy for the hole transfer were reduced significantly upon cyanation of anthracene, especially at the 9,10-positions of anthracene, and the origin of the reduction was attributed to the enhanced electron localization on the $\mathrm{CN}$ group in the highest occupied molecular orbital (HOMO). This ionization led the molecules in "latitudinal" expansion, and such an expansion seemed to reduce the reorganization energies of molecules, especially at the compounds $\mathbf{4}$ and $\mathbf{6}$.

The increased reorganization energy of electron hopping in anthracene was attributed to the additional longitudinal expansion of the molecule, and the effect upon cyanation on the electron hopping in cyanoanthracene was not that large compared to the hole hopping.

The cyanation of anthracene reduced the band gap significantly, and the 9,10-dicyanoanthracene showed the lowest band gap. The present study provides an opportunity for the design of novel functional organic materials for the relevant field of organic thin film transistors (OTFTs).

Acknowledgments. The authors wish to thank the Ministry of Commerce, Industry and Energy of Korea through the 21C Frontier program (F0004010-2009-32) for the financial support. $\mathrm{K}$. Yang is grateful to Professor Jeffrey R. Reimers at the School of Chemistry, University of Sydney, Australia, for making DUSHIN program available.

\section{References}

1. Garnier, F.; Hajlaoui, R.; Yassar, A.; Srivastava, P. Science 1994, 265,1684

2. Horowitz, G.; Fichou, D.; Peng, X. Z.; Xu, Z. G.; Garnier, F. Solid State Commun. 1989, 72, 381.

3. Horowitz, G. Adv. Mater. 1998, 10, 365.

4. Sirringhaus, H.; Brown, P. J.; Friend, R. H.; Nielsen, M. M.; Bechgaard, K.; Langeveld-Voss, B. M. W.; Spiering, A. J. H.; Janssen, R. A. J.; Meijer, E. W.; Herwig, P.; De Leeuw, D. M. Nature (London) 1999, 401, 685.

5. Katz, H. E.; Lovinger, A. J.; Johnson, J.; Kloc, C.; Siegrist, T.; Li, W.; Lin, Y. Y.; Dodabalapur, A. Nature (London) 2000, 404, 478.

6. Tang, C. W.; VanSlyke, S. A. Appl. Phys. Lett. 1987, 51, 913.

7. Burroughes, J. H.; Bradley, D. D. C.; Brown, A. R.; Marks, R. N.; Mackay, K.; Friend, R. H.; Burns, P. L.; Holmes, A. B. Nature (London) 1990, 347, 539.

8. Sheats, J. R.; Antoniadis, H.; Hueschen, M.; Leonard, W.; Miller, J.; Moon, R.; Roitman, D.; Stocking, A. Science 1996, 273, 884.

9. Friend, R. H.; Gymer, R. W.; Holmes, A. B.; Burroughes, J. H.; Marks, R. N.; Taliani, C.; Bradley, D. D. C.; Dos Santos, D. A.;
Brédas, J. L.; Logdlund, M.; Salaneck, W. R. Nature (London) 1999, 397, 121.

10. Sariciftci, N. S.; Smilowitz, L.; Heeger, A. J.; Wudl, F. Science 1992, 258, 1474.

11. Halls, J. J. M.; Walsh, C. A.; Greenham, N. C.; Marseglia, E. A.; Friend, R. H.; Moratti, S. C.; Holmes, A. B. Nature (London) 1995, 376, 498.

12. Yu, G.; Wang, J.; McElvain, J.; Heeger, A. J. Adv. Mater. 1998, 10, 1431.

13. Brabec, C. J.; Sariciftci, N. S.; Hummelen, J. C. Adv. Funct. Mater. 2001, 11, 15.

14. Katz, H. E. J. Mater. Chem. 1997, 7, 369.

15. Nelson, S. F.; Lin, Y. Y.; Gundlach, D. J.; Jackson, T. N. Appl. Phys. Lett. 1998, 72, 1854.

16. Klauk, H.; Gundlach, D. J.; Bonses, M.; Kuo, C. C.; Jackson, T. N. Appl. Phys. Lett. 2000, 76, 1692.

17. Kelley, T. W.; Muyres, D. V.; Baude, P. F.; Smith, T. P.; Jones, T. D. Mater. Res. Soc. Symp. Proc. 2003, 771, 169.

18. Yamada, M.; Ikemote, I.; Kuroda, H. Bull. Chem. Soc. Jpn. 1988, $61,1057$.

19. Kagan, C. R.; Afzali, A.; Graham, T. O. Appl. Phys. Lett. 2005, $86,193505$.

20. Herwig, P. T.; Müllen, K. Adv. Mater.1999, 11, 480.

21. Anthony, J. E.; Brooks, J. S.; Eaton, D. L.; Parkin, S. R. J. Am. Chem. Soc. 2001, 123, 9482.

22. Anthony, J. E.; Eaton, D. L.; Parkin, S. R. Org. Lett. 2002, 4, 15.

23. Meng, H.; Bendikov, M.; Mitchell, G.; Helgeson, R.; Wudl, F.; Bao, Z.; Siegrist, T.; Kloc, C.; Chen, C. H. Adv. Mater. 2003, 15, 1090.

24. Miao, Q.; Nguyen, T. Q.; Someya, T.; Blanchet, G. B.; Nuckolls, C. J. Am. Chem. Soc. 2003, 125, 10284.

25. Kim. Y. H; Kwon, S. K.; Yoo, D. S.; Rubner, M. F.; Wrighton, M. S. Chem. Mater. 1997, 9, 2699.

26. (a) Shi, J.; Tang, C. W. Appl. Phys. Lett. 2002, 80, 3201. (b) Liu, T. H.; Shen, W. J.; Balaganesan, B.; Yen, C. K.; Iou, C. Y.; Chen, H. H.; Chen, C. H. Synth. Met. 2003, 137, 1033. (c) Lin, J.-H.; Elangovan, A.; Ho, T.-I. J. Org. Chem. 2005, 70, 7397.

27. Kim, Y-H.; Jeong, H-C.; Kim, S-H.; Yang, K.; Kwon, S-K. Adv. Funct. Mater. 2005, 15, 1799.

28. Curtis, M. D.; Cao, J.; Kampf, J. W. J. Am. Chem. Soc. 2004, 126, 4318.

29. Koh, S. E.; Risko, C.; de Silva Filho, D. A.; Kwon, O.; Facchetti, A.; Brédas, J. L.; Marks, T. J.; Ratner, M. A. Adv. Funct. Mater. 2008, 18,332 .

30. Hapiot, P.; Demanze, F.; Yassar, A.; Garnier, F. J. Phys. Chem. 1996, 100, 8397.

31. Hutchison, G. R.; Ratner, M. A.; Marks, T. J. J. Am. Chem. Soc. 2005, 127, 2339 .

32. De Oliveira, M. A.; Dos Santos, H. F.; De Almeida, W. B. In. J. Quan. Chem. 2002, 90, 603

33. Parr, R. G.; Yang, W. Density-Functional Theory of Atoms and Molecules; Oxford University Press: New York, 1989.

34. Kuo, M.-Y.; Chen, H.-Y.; Chao, I. Chem. Eur.J. 2007, 13, 4750.

35. Brédas, J. L.; Beljonne, D.; Coropceanu, V.; Cornil, J. Chem. Rev. 2004, 104, 4971 and references cited therein.

36. Marcus, R. A. Rev. Mod. Phys. 1993, 65, 599.

37. (a) Brédas, J.-L.; Calbert, J. P.; da Silva Filho, D. A.; Cornil, J. Proc. Natl. Acad. Sci. USA 2002, 99, 5804. (b) Park, Y. H.; Yang, K.; Kim, Y.-H.; Kwon, S. K. Bull. Korean Chem. Soc. 2007, 28, 1358.

38. Balzani, V., Ed. Electron Transfer in Chemistry; Wiley-VCH: Weinheim, 2001.

39. (a) Bixon, M., Jortner, J., Eds.; Electron Transfer: From Isolated Molecules to Biomolecules; Wiley: New York, 1999; Vols. 106107. (b) Marcus, R. A. J. Chem. Phys. 1956, 24, 966 and 979. (c) Marcus, R. A.; Sutin, N. Biochim. Biophys. Acta 1985, 811, 265.

40. Reimers, J. R. J. Chem. Phys. 2001, 115, 9103.

41. Silinsh, E. A.; Klimkans, A.; Larsson, S.; Capek, V. Chem. Phys. 
1995, 198, 311.

42. Frisch, M. J.; Trucks, G. W.; Schlegel, H. B.; Scuseria, G. E.; Robb, M. A.; Cheeseman, J. R.; Zakrzewski, V. G.; Montgomery, J. A., Jr.; Stratmann, R. E.; Burant, J. C.; Dapprich, S.; Millam, J. M.; Daniels, A. D.; Kudin, K. N.; Strain, M. C.; Farkas, O.; Tomasi, J.; Barone, V.; Cossi, M.; Cammi, R.; Mennucci, B.; Pomelli, C.; Adame, C.; Clifford, S.; Ochterski, J.; Petersson, G. A.; Ayala, P. Y.; Cui, Q.; Morokuma, K.; Salvador, P.; Dannenberg, J.J.; Malick, D. K.; Rabuck, A. D.; Raghavachari, K.; Foresman, J. B.; Cioslowski, J.; Ortiz, J. V.; Baboul, A. G.; Stefanov, B. B.; Liu, G.; Liashenko, A.; Piskorz, P.; Komaromi, I.; Gomperts, R.; Martin, R. L.; Fox, D. J.; Keith, T.; Al-Laham, M. A.; Peng, C. Y.; Nanayakkara, A.; Challacombe, M.; Gill, P. M.W.; Johnson, B.; Chen, W.; Wong, M. W.; Andres, J. L.; Gonzalez, C.; Head-Gordon, M.; Replogle, E. S.;
Pople, J. A. Gaussian 98, Revision A.7: Gaussian, Inc., Pittsburgh, PA, 1998.

43. Lee, C.; Yang, W.; Parr, R. G. Phys. Rev. B 1988, 37, 785.

44. (a) Zerner, M. C.; Correa de Mello, P.; Hehenberger, M. Int. J. Quant. Chem. 1982, 21, 251. (b) Hanson, L. K.; Fajer, J.; Thompson, M. A.; Zerner, M. C. J. Am. Chem. Soc. 1987, 109, 4728.

45. Hammett, L. P. J. Am. Chem. Soc. 1937, 59, 96.

46. Coropceanu, V.; Malagoli, M.; da Silva Filho, D. A.; Gruhn, N. E.; Bill, T. G.; Brédas, J. L. Phys. Rev. Lett. 2002, 89, 275503.

47. Janak, J. F. Phys. Rev. B 1978, 18, 7165.

48. (a) Sebastian, L.; Weiser, G.; Bässler, H. Chem. Phys. 1981, 61, 125. (b) Sebastian, L.; Weiser, G.; Peter, G.; Bässler, H. Chem. Phys. 1983, 75, 103. (c) Bounds, P. J.; Siebrand, W. Chem. Phys. Letters 1980, 75, 414. 